\title{
The role of vibrationally excited nitrogen and oxygen in the ionosphere over Millstone Hill during 16-23 March, 1990
}

\author{
A. V. Pavlov ${ }^{1,2}$, K.-I. Oyama ${ }^{2}$ \\ ${ }^{1}$ Institute of Terrestrial Magnetism, Ionosphere and Radio-Wave Propagation, Russia Academy of Science (IZMIRAN), \\ Troitsk, Moscow Region, 142092, Russia \\ ${ }^{2}$ Institute of Space and Astronautical Science (ISAS), 3-1-1 Yoshinodai, Sagamihara, Kanagawa, 229-8510, Japan
}

Received: 22 October 1999 / Revised: 9 February 2000 / Accepted: 2 March 2000

\begin{abstract}
We present a comparison of the observed behavior of the $\mathrm{F}$ region ionosphere over Millstone Hill during the geomagnetically quiet and storm period on 16-23 March, 1990, with numerical model calculations from the time-dependent mathematical model of the Earth's ionosphere and plasmasphere. The effects of vibrationally excited $\mathrm{N}_{2}(v)$ and $\mathrm{O}_{2}(v)$ on the electron density and temperature are studied using the $\mathrm{N}_{2}(v)$ and $\mathrm{O}_{2}(v)$ Boltzmann and non-Boltzmann distribution assumptions. The deviations from the Boltzmann distribution for the first five vibrational levels of $\mathrm{N}_{2}(v)$ and $\mathrm{O}_{2}(v)$ were calculated. The present study suggests that these deviations are not significant at vibrational levels $v=1$ and 2, and the calculated distributions of $\mathrm{N}_{2}(v)$ and $\mathrm{O}_{2}(v)$ are highly non-Boltzmann at vibrational levels $v>2$. The $\mathrm{N}_{2}(v)$ and $\mathrm{O}_{2}(v)$ non-Boltzmann distribution assumption leads to the decrease of the calculated daytime NmF2 up to a factor of 1.44 (maximum value) in comparison with the $\mathrm{N}_{2}(v)$ and $\mathrm{O}_{2}(v)$ Boltzmann distribution assumption. The resulting effects of $\mathrm{N}_{2}(v>0)$ and $\mathrm{O}_{2}(v>0)$ on the $\mathrm{NmF} 2$ is the decrease of the calculated daytime NmF2 up to a factor of 2.8 (maximum value) for Boltzmann populations of $\mathrm{N}_{2}(v)$ and $\mathrm{O}_{2}(v)$ and up to a factor of 3.5 (maximum value) for non-Boltzmann populations of $\mathrm{N}_{2}(v)$ and $\mathrm{O}_{2}(v)$. This decrease in electron density results in the increase of the calculated daytime electron temperature up to about 1040-1410 K (maximum value) at the F2 peak altitude giving closer agreement between the measured and modeled electron temperatures. Both the daytime and nighttime densities are not reproduced by the model without $\mathrm{N}_{2}(v>0)$ and $\mathrm{O}_{2}(v>0)$, and inclusion of vibrationally excited $\mathrm{N}_{2}$ and $\mathrm{O}_{2}$ brings the model and data into better agreement. The effects of vibrationally excited $\mathrm{O}_{2}$ and $\mathrm{N}_{2}$ on the electron density and temperature are most pronounced during daytime.
\end{abstract}

Correspondence to: A. V. Pavlov e-mail: pavlov@charley.izmiran.rssi.ru
Key words: Ionosphere (ion chemistry and composition; ionosphere-atmosphere interactions; ionospheric disturbances).

\section{Introduction}

The $\mathrm{O}^{+}\left({ }^{4} \mathrm{~S}\right)$ ions that predominate in the ionospheric $\mathrm{F} 2$-region are lost in the reactions

$\mathrm{O}^{+}\left({ }^{4} \mathrm{~S}\right)+\mathrm{N}_{2}(v) \longrightarrow \mathrm{NO}^{+}+\mathrm{N}$,

$\mathrm{O}^{+}\left({ }^{4} \mathrm{~S}\right)+\mathrm{O}_{2}(v) \longrightarrow \mathrm{O}_{2}^{+}+\mathrm{O}$

with the loss rate

$\mathrm{L}=\mathrm{K}\left[\mathrm{N}_{2}\right]+\beta\left[\mathrm{O}_{2}\right]$,

where $v=0,1, \ldots$ is the number of the vibrational level of $\mathrm{N}_{2}$ or $\mathrm{O}_{2}$, the effective rate coefficients of reactions (1), and (2) are determined as

$$
\mathrm{K}=\sum_{v=0}^{\infty}\left[\mathrm{N}_{2}(v)\right] K_{v} /\left[\mathrm{N}_{2}\right], \quad \beta=\sum_{v=0}^{\infty}\left[\mathrm{O}_{2}(v)\right] \beta_{v} /\left[\mathrm{O}_{2}\right],
$$

$K_{v}$ is the recombination rate coefficient of $\mathrm{O}^{+}\left({ }^{4} \mathrm{~S}\right)$ ions with $\mathrm{N}_{2}(v), \beta_{v}$ is the recombination rate coefficient of $\mathrm{O}^{+}\left({ }^{4} \mathrm{~S}\right)$ ions with $\mathrm{O}_{2}(v),\left[\mathrm{N}_{2}\right]=\sum_{v=0}^{\infty}\left[\mathrm{N}_{2}(v)\right],\left[\mathrm{O}_{2}\right]=$ $\sum_{v=0}^{\infty}\left[\mathrm{O}_{2}(v)\right],\left[\mathrm{N}_{2}(v)\right]$ and $\left[\mathrm{O}_{2}(v)\right]$ are the number densities of $\mathrm{N}_{2}$ and $\mathrm{O}_{2}$ at the $v$-th vibrational level.

Schmeltekopf et al. (1968) measured $K\left(T_{v}\right)$ over the vibrational temperature range $300-6000 \mathrm{~K}$, and found the $K_{v} / K_{0}$ ratios from the measured $K\left(T_{v}\right)$ for $T_{n}=T_{i}=300 \mathrm{~K}$ where $T_{v}$ is the vibrational temperature of $\mathrm{N}_{2}, T_{n}$ is the neutral temperature, and $T_{i}$ is the ion temperature. The fundamental results of Schmeltekopf et al. (1968) were confirmed by Ferguson et al. (1984). The measurements of $K$ were given by Hierl et al. (1997) over the temperature range $300-1600 \mathrm{~K}$ for $T_{n}=T_{i}=T_{v}$. These results confirm the observations of Schmeltekopf et al. (1968), and show for the first time that the translation temperature dependencies of $K_{v}$ are similar to $K_{0}$. 
In an earlier study, Richards et al. (1994) and Pavlov and Buonsanto (1997) compared the calculated electron densities and temperatures with the data for the 16-23 March, 1990, geomagnetic storm (Buonsanto et al., 1992). Richards et al. (1994) and Pavlov and Buonsanto (1997) evaluated the effects of $\mathrm{N}_{2}(v>0)$ on the peak electron densities, NmF2, as about factors of 2-4 reductions in the daytime NmF2. Pavlov and Buonsanto (1997) found that the calculated distribution is highly non-Boltzmann at vibrational levels $v>2$, and the Boltzmann distribution assumption results in the increase of $10-30 \%$ in calculated $\mathrm{NmF} 2$ during the stormtime periods. However, the calculations of Pavlov and Buonsanto (1997) were based on the translation temperature dependencies of $K_{v}$ given by the theory of Van Zandt and O'Malley (1973), while Pavlov (1998b) and Pavlov et al. (1999) found that the $K\left(T_{n}\right)$ prediction of the Van Zandt and O'Malley (1973) theory do not agree with the recent measurements of $K\left(T_{n}\right)$ given by Hierl et al. (1997). In this study we examine the effects of $\mathrm{N}_{2}(v)$, and the difference between Boltzmann and nonBoltzmann distributions of $\mathrm{N}_{2}(v)$ on the electron density and temperature during the undisturbed and storm period of 16-23 March, 1990, by the use of the $K_{v} / K_{0}$ ratios given by Hierl et al. (1997), and the value of $K_{0}$ measured by Albritton et al. (1977).

Hierl et al. (1997) found a big difference between the high temperature flowing afterglow and drift tube measurements (McFarland et al., 1973; Albritton et al., 1977) of $\beta$ as a result of the input of the reactions between the vibrationally excited $\mathrm{O}_{2}$ and $\mathrm{O}^{+}\left({ }^{4} \mathrm{~S}\right)$, and determined the dependence of $\beta$ on the $\mathrm{O}_{2}$ vibrational temperature, $T_{v i b}$, over the temperature range 300-1800 for $T_{v i b}=T_{n}=T_{i}$. The flowing afterglow measurements of $\beta$ given by Hierl et al. (1997) were used by Pavlov (1998b) to invert the data to give the rate coefficients $\beta_{v}$ for the various vibrational levels of $\mathrm{O}_{2}(v>0)$ for the model of the Boltzmann distribution of vibrationally excited molecular oxygen.

The difference between the measurements of $\beta$ given by Hierl et al. (1997) and the scaled drift tube data is decreased with the decrease in $T_{n}$. As a result, as for $\mathrm{N}_{2}(v)$, the effects of the vibrational excitation of $\mathrm{O}_{2}$ are expected to be more important during solar maximum than at solar minimum. First studies of the $\mathrm{O}_{2}(v>0)$ effects on NmF2 for the 6-12 April, 1990, storm (Pavlov, 1998b) and the 5-11 June, 1991, storm (Pavlov et al., 1999) found that enhanced vibrational excitation of $\mathrm{O}_{2}$ leads up to the $40 \%$ decrease in the calculated $\mathrm{NmF} 2$ at solar maximum. Here we study the effects of $\mathrm{O}_{2}(v>0)$ on $\mathrm{NmF} 2$ for the 16-23 March, 1990, geomagnetic storm which was at high solar-activity conditions (Buonsanto et al., 1992). We examine also the effects of Boltzmann and non-Boltzmann distributions of $\mathrm{O}_{2}(v)$ on the electron density and temperature during the March 1990 geomagnetic storm. We compare our results with previous modeling results given by Richards et al. (1994) and Pavlov and Buonsanto (1997) for the 16-23 March, 1990, period where the effects of $\mathrm{O}_{2}(v>0)$ on the electron density and temperature were not taken into account.
We also study the electron energy balance of the ionosphere at Millstone Hill during 16-23 March, 1990. The anomalous nighttime electron temperature events were observed over less than a third of the time studied in the fall and spring months over Millstone Hill (Garner et al., 1994), and unusually high electron temperatures in the nighttime ionosphere over Millstone Hill were also observed during the periods 20-23 March, 1990, (Buonsanto et al., 1992). The existence of anomalous nighttime temperature events in the fall and spring months argues against a simple relationship of these anomalous temperature enhancements to conjugate photoelectrons. The physical origin of these temperature events is still unclear. Following Balan et al. (1996) and Richards and Khazanov (1997), we believe that there is an additional heating rate of the electron in the plasmasphere, and we evaluate the value of this additional heating rate so that an agreement between the measured and modeled electron temperature is obtained during the studied period.

The thermal electron impact excitation of the fine structure levels of the ${ }^{3} \mathrm{P}$ ground state of atomic oxygen is presently believed to be one of the dominant electron cooling processes in the $\mathrm{F}$ region of the ionosphere (Richards et al., 1986; Richards and Khazanov, 1997). Pavlov (1998a, c) and Pavlov and Berrington (1999) have revised and evaluated the electron cooling rates by vibrational and rotational excitation of $\mathrm{N}_{2}$ and $\mathrm{O}_{2}$, and the electron cooling rate by electron impact excitation of fine-structure levels of atomic oxygen. Pavlov and Berrington (1999) found that the role of the cooling rate of thermal electrons by electron impact excitation of fine structure levels of atomic oxygen is not significant at the F2-peak altitudes of the ionosphere for the geomagnetically quiet and disturbed period on 6-12 April, 1990, above Millstone Hill, and the energy exchange between the electron and ion gases and the electron cooling rates by vibrational excitation of $\mathrm{O}_{2}$ and $\mathrm{N}_{2}$ are the largest cooling rates above $160 \mathrm{~km}$. The new analytical expressions for cooling rates given by Pavlov (1998a, c) and Pavlov and Berrington (1999) are applied to perform an examination the role of these electron cooling rates in the thermal balance of the ionosphere during the undisturbed and storm period of 16-23 March, 1990.

\section{Theoretical model}

The model used is the IZMIRAN model that we have steadily developed over the years (Pavlov, 1997; 1998a, b, c; Pavlov et al., 1999; Pavlov and Berrington, 1999). Schematic illustration of the major input and output elements of the model code, and the flowchart of the solution are shown in Fig. 1. It is a one dimensional model that uses a titled dipole approximation to the Earth's magnetic field and takes into account the offset between the geographic and geomagnetic axes. In the model, coupled time dependent equations of continuity and energy balance, and diffusion equations for electrons, and $\mathrm{O}^{+}\left({ }^{4} \mathrm{~S}\right), \mathrm{H}^{+}$, and $\mathrm{He}^{+}$ions are solved along a centered-dipole magnetic field line for the concentra- 
THE MODEL OF THE THERMAL PLASMA IN THE IONOSPHERE AND PLASMASPHERE

INPUT: LT, DATE, LATITUDE, LONGITUDE, 3 HOUR Ap INDICES, F10.7, <F10.7> OUTPUT: ELECTRON AND ION DENSITIES AND TEMPERATURES, [ $\mathrm{N}_{2}(\mathrm{v}=1-5)$ ] $\left[\mathrm{O}_{2}(\mathrm{~V}=1-5)\right],[\mathrm{O}(\mathrm{D})]$

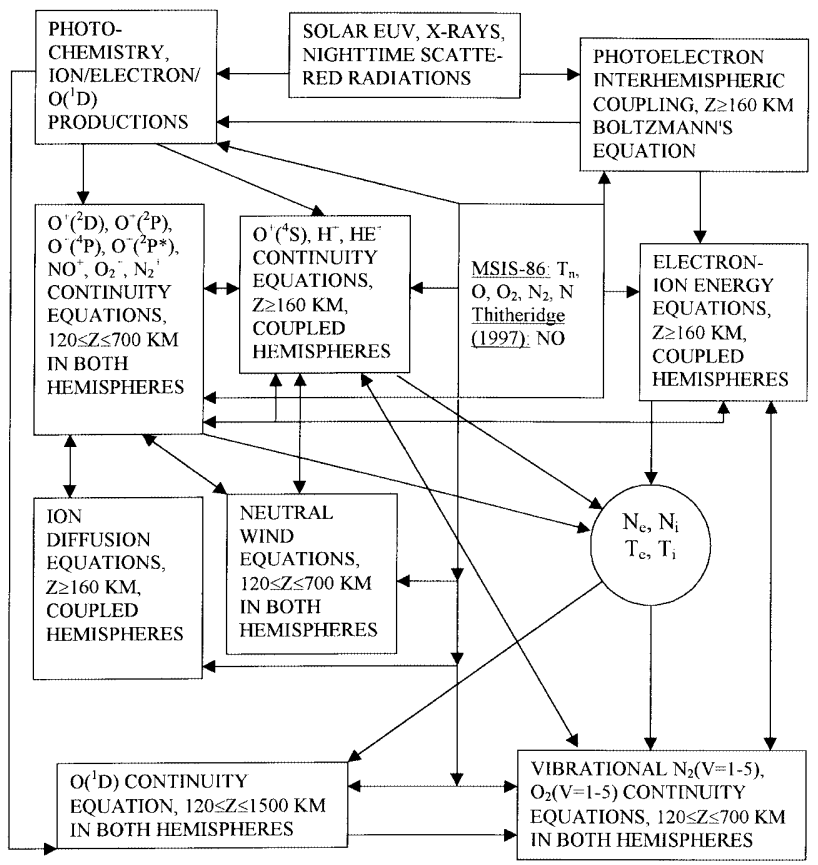

Fig. 1. Schematic illustration of the major input and output elements of the IZMIRAN model code and the flowchart of the solution

tions, temperatures, and field-aligned diffusion velocities of ions and electrons from a base altitude $(160 \mathrm{~km})$ in the Northern Hemisphere through the plasmasphere to the same base altitude in the Southern Hemisphere. Electron heating due to photoelectrons is provided by a solution of the Boltzmann equation for photoelectron flux. In the altitude range $120-700 \mathrm{~km}$ in the Northern and Southern Hemispheres the model solves time dependent continuity equations for $\mathrm{O}^{+}\left({ }^{2} \mathrm{D}\right), \mathrm{O}^{+}\left({ }^{2} \mathrm{P}\right)$, $\mathrm{NO}^{+}, \mathrm{O}_{2}^{+}, \mathrm{N}_{2}^{+}, \mathrm{N}_{2}(v=1, \ldots, 5)$, and $\mathrm{O}_{2}(v=1, \ldots, 5)$, and vibrationally excited nitrogen and oxygen quanta $\left.\alpha=\sum_{v} v\left[\mathrm{~N}_{2}(v)\right] / \mathrm{N}_{2}\right]$ and $\delta=\sum_{v} v\left[\mathrm{O}_{2}(v)\right] /\left[\mathrm{O}_{2}\right]$. An additional production of $\mathrm{O}^{+}\left({ }^{4} \mathrm{~S}\right), \mathrm{O}^{+}\left({ }^{2} \mathrm{D}\right)$, and $\mathrm{O}^{+}\left({ }^{2} \mathrm{P}\right)$ ions is that described by Pavlov (1998b), and obtained in the IZMIRAN model by inclusion of $\mathrm{O}^{+}\left({ }^{4} \mathrm{~S}\right)$, and $\mathrm{O}^{+}\left({ }^{2} \mathrm{P}^{*}\right)$ ions. The model calculates $\left[\mathrm{O}\left({ }^{1} \mathrm{D}\right)\right]$ from a timedependent continuity equation in the region between 120 and $1500 \mathrm{~km}$ in altitude in both hemispheres. The diffusion of ions and excited species are considered in continuity equations for $\mathrm{NO}^{+}, \mathrm{O}_{2}^{+}, \mathrm{O}_{2}(v), \mathrm{N}_{2}(v)$, and $\mathrm{O}\left({ }^{1} \mathrm{D}\right)$, while densities of $\mathrm{O}^{+}\left({ }^{2} \mathrm{D}\right), \mathrm{O}^{+}\left({ }^{2} \mathrm{P}\right)$, and $\mathrm{N}_{2}^{+}$are obtained from local chemical equilibrium. The updated IZMIRAN model uses the dissociative recombination rate coefficient for $\mathrm{N}_{2}^{+}$ions measured by Peterson et al. (1998). The revised electron cooling rates by vibrational and rotational excitation of $\mathrm{O}_{2}$ and $\mathrm{N}_{2}$, and by electron impact excitation of fine structure levels of atomic oxygen given by Pavlov $(1998 \mathrm{a}, \mathrm{c})$ and Pavlov and Berrington (1999) are included in the IZMIRAN model.

The full IZMIRAN model solves time dependent continuity equations for number densities $\mathrm{N}_{2}(v=$
$1, \ldots, 5)$ and $\mathrm{O}_{2}(v=1, \ldots, 5)$, and includes the option to use the model of the Boltzmann distribution of vibrationally excited molecular nitrogen and oxygen as

$$
\begin{aligned}
& {\left[\mathrm{N}_{2}(v)\right]_{\mathrm{B}}=\left[\mathrm{N}_{2}(0)\right] \exp \left(-v E_{1} T_{v}^{-1}\right),} \\
& {\left[\mathrm{O}_{2}(v)\right]_{\mathrm{B}}=\left[\mathrm{O}_{2}(0)\right] \exp \left(-v E_{1}^{\prime} T_{v i b}^{-1}\right),}
\end{aligned}
$$

where $E_{1}=3353 \mathrm{~K}$ and $E_{1}^{\prime}=2239 \mathrm{~K}$ are the energies of the first vibrational levels of $\mathrm{N}_{2}$ and $\mathrm{O}_{2}$ (Radzig and Smirnov, 1980), $\left[\mathrm{N}_{2}(0)\right]=\left[\mathrm{N}_{2}\right]\left\{1-\exp \left(-E_{1} T_{v}^{-1}\right)\right\}$, $\left[\mathrm{O}_{2}(0)\right]=\left[\mathrm{O}_{2}\right]\left\{1-\exp \left(-E_{1} T_{v i b}^{-1}\right)\right\}$, the values of the vibrational temperatures, $T_{v}$ and $T_{v i b}$, of $\mathrm{N}_{2}$ and $\mathrm{O}_{2}$ are calculated by solving the time-dependent continuity equations for vibrationally excited nitrogen and oxygen quanta given by Pavlov ( 1997, 1998b), and using the relationships $T_{v}=-E_{1} / \ln \left[\alpha(1+\alpha)^{-1}\right]$ and $T_{v i b}=-E_{1}^{\prime} /$ $\ln \left[\delta(1+\delta)^{-1}\right]$ (see Pavlov and Buonsanto, 1997; Pavlov, 1997, 1998b).

The heating rate of the electron gas by photoelectrons is calculated along a centered - dipole magnetic field line using the numerical method of Krinberg and Tachilin (1984) for the determination of the photoelectron fluxes within a plasmaspheric field tube on the same field line grid that is used in solving for the temperatures. The updated IZMIRAN model solves the Boltzmann equation for photoelectron flux using the updated elastic and inelastic crosssections of the neutral components of the atmosphere. For $\mathrm{O}$, the elastic cross section employed in the electron transport code was drawn from the work of Williams and Allen (1989) for energies below $8.7 \mathrm{eV}$, and, above $8.7 \mathrm{eV}$, we have adopted the elastic cross section of Joshipura and Patel (1993). The $\mathrm{N}_{2}$ elastic cross section of Iticawa (1994) for electron energies is used in our model. The $\mathrm{O}$ and $\mathrm{N}_{2}$ inelastic cross sections are given by Majed and Strickland (1997), and we employ these cross sections with some modification for $\mathrm{N}_{2}$. The $\mathrm{N}_{2}$ vibrational excitation cross sections used by Majed and Strickland (1997) in calculations of the $\mathrm{N}_{2}$ inelastic cross section were replaced by the $\mathrm{N}_{2}$ vibrational excitation cross sections of Robertson et al. (1997) for vibrational levels $v=1$ and 2, and those of Schulz (1976) for $v=3-10$ with the normalization factor of 0.7 (see details in Pavlov 1998a). For $\mathrm{O}_{2}$, the elastic and inelastic cross sections are taken from Kanic et al. (1993).

The model uses the recombination rate coefficient of $\mathrm{O}^{+}\left({ }^{4} \mathrm{~S}\right)$ ions with unexcited $\mathrm{N}_{2}(0)$ and $\mathrm{O}_{2}(0)$ (Albritton et al., 1977; St.-Maurice and Torr, 1978) and vibrationally excited $\mathrm{N}_{2}(v)$ and $\mathrm{O}_{2}(v)$ (Schmeltekopf et al., 1968; Hierl et al., 1997; Pavlov, 1998b) as described in detail by Pavlov (1998b) and Pavlov et al. (1999). The energy balance equations for ions of the model consider the perpendicular component, $E_{\perp}$, of the electric field with respect to the geomagnetic field and the rate coefficients of such important ionospheric processes as the reactions of $\mathrm{O}^{+}\left({ }^{4} \mathrm{~S}\right)$ with $\mathrm{N}_{2}$ and $\mathrm{O}_{2}$, and $\mathrm{N}_{2}^{+}$with $\mathrm{O}_{2}$ which depend on effective temperatures which are functions of the ion temperature, the neutral temperature and $E_{\perp}$ (Pavlov, 1997, 1998b). The measured value of $E_{\perp}$ can be used as an input parameter for our theoretical model. 
The key inputs to the IZMIRAN model are the concentrations and temperature of the neutral constituents, the solar EUV fluxes, and the plasma drift velocity. The neutral temperature and densities are supplied by the MSIS-86 model of Hedin (1987) using 3-h $A p$ indices. To calculate the density of NO the model given by Titheridge (1997) is used. The solar EUV fluxes are supplied by the EUV97 model (Tobiska and Eparvier, 1998) for the model calculations. At night our model includes the neutral ionization by scattered solar 121.6, 102.6 and $58.4 \mathrm{~nm}$ fluxes (Pavlov, 1997). In the Northern Hemisphere instead of calculating thermospheric wind components by solving the momentum equations, the model calculates an equivalent neutral wind from the hmF2 measurements using the modified method of Richards (1991) described by Pavlov and Buonsanto (1997). For the Southern Hemisphere where we do not have observed hmF2 momentum equations for the horizontal components of the thermospheric wind are calculated in the altitude range $120-700 \mathrm{~km}$ to derive an equivalent plasma drift velocity, as described by Pavlov (1997).

\section{Undisturbed period and storms of 16-23 March, 1990}

The undisturbed conditions of 16-17 March, 1990, (Ap between 3 and 8) and the 18-23 March, 1990, magnetic storms ( $A p$ between 14 and 73) were periods wich occurred at solar maximum when the 10.7 solar flux varied between 180 on March 16 and 247 on March 23 .
During the 16-23 March, 1990, period two geomagnetic storms took place with a gradual commencement time near 04:00 UT on March 18 (a minor storm) and with a sudden commencement time near 22:45 UT on March 20 (a major storm). The measured electron densities and temperatures, and the perpendicular electric fields (with respect to the magnetic field) used were taken by the incoherent scatter radar at Millstone Hill, Massachusetts (Buonsanto et al., 1992).

\subsection{Effects of vibrational excited oxygen and nitrogen on electron density and temperature}

Figure 2 displays the measured (crosses) and calculated (lines) NmF2 (bottom panel), hmF2 (middle panel), and the electron temperature, $T_{e m}$, at the F2 peak altitude (top panel) above Millstone Hill for the magnetically quiet and disturbed period 16-23 March, 1990. Solid lines show the IZMIRAN model results when the Boltzmann distribution of $\mathrm{N}_{2}(v)$ and $\mathrm{O}_{2}(v)$ is used. Dotted lines represent the results obtained from the IZMIRAN model with effects of $\mathrm{N}_{2}(v>0)$ and $\mathrm{O}_{2}(v>0)$ on the $\mathrm{O}^{+}\left({ }^{4} \mathrm{~S}\right)$ loss rate and the heating rate of electrons due to the deexcitation reactions of vibrationally excited $\mathrm{N}_{2}$ and $\mathrm{O}_{2}$ using the non-Boltzmann populations of the first five vibrational levels of $\mathrm{N}_{2}(v)$ and $\mathrm{O}_{2}(v)$. The values of the deviations of $\left[\mathrm{N}_{2}(v)\right]$ from $\left[\mathrm{N}_{2}(v)\right]_{B}$ and $\left[\mathrm{O}_{2}(v)\right]$ from $\left[\mathrm{O}_{2}(v)\right]_{B}$ will be discussed later.

It can be seen from Fig. 2 that the modeled electron densities and temperatures are in reasonable accord with

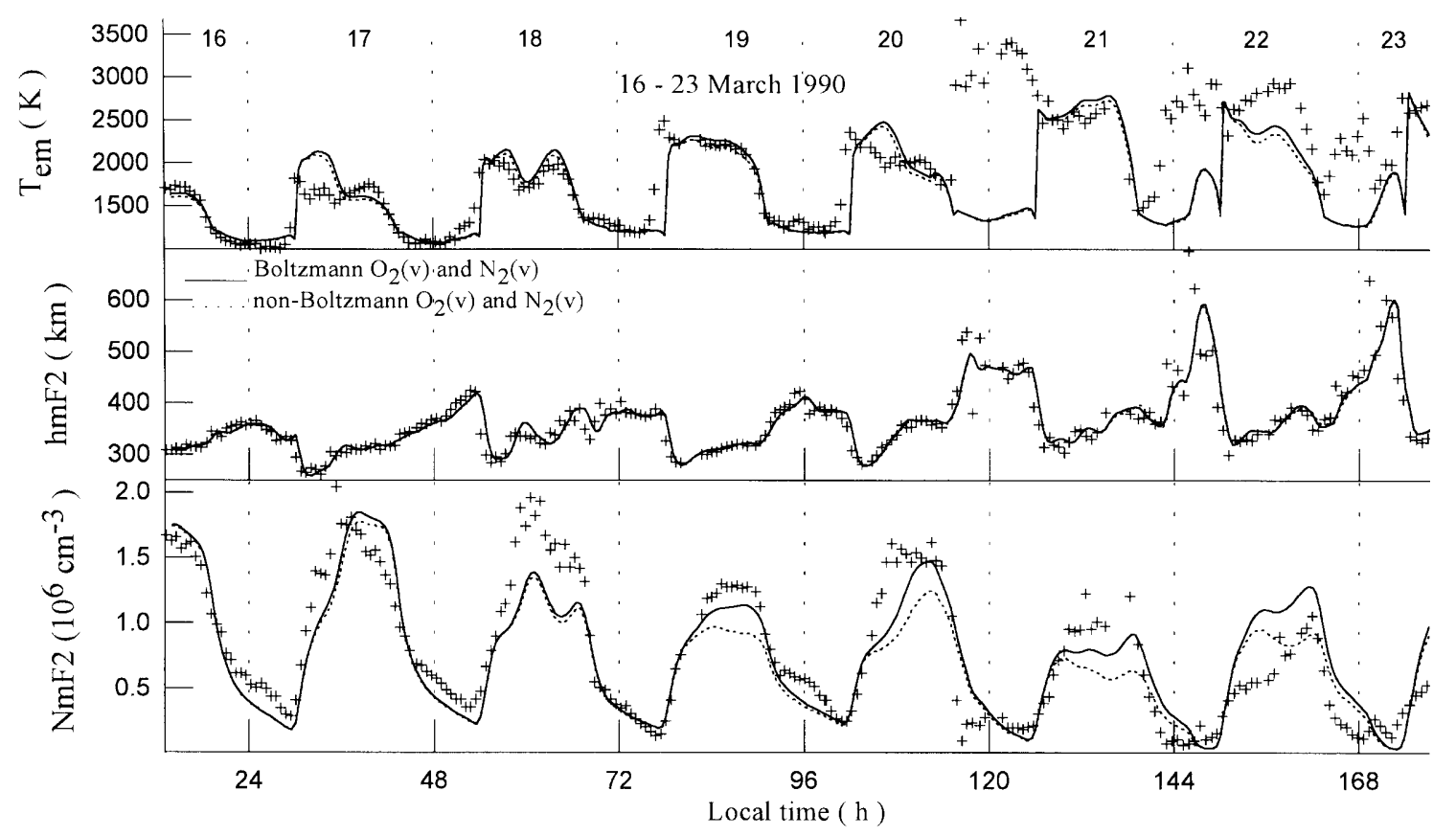

Fig. 2. The measured (crosses) and calculated (lines) NmF2 (bottom panel), hmF2 (middle panel), and the electron temperature, $T_{e m}$, at the F2 peak altitude (top panel) above Millstone Hill for the magnetically quiet and disturbed period 16-23 March, 1990. Solid lines show the IZMIRAN model results when the Boltzmann populations of $\mathrm{N}_{2}(v)$ and $\mathrm{O}_{2}(v)$ are used. Dotted lines represent the results obtained from the IZMIRAN model with effects of $\mathrm{N}_{2}(v>0)$ and $\mathrm{O}_{2}(v>0)$ on the $\mathrm{O}^{+}\left({ }^{4} \mathrm{~S}\right)$ loss rate and the heating rate of electrons due to the de-excitation reactions of vibrationally excited molecular nitrogen and oxygen using the non-Boltzmann populations of the first five vibrational levels of $\mathrm{N}_{2}(v)$ and $\mathrm{O}_{2}(v)$. The local time start is $13: 00$ 
the observed values if the Boltzmann vibrational $\mathrm{N}_{2}$ and $\mathrm{O}_{2}$ distribution assumptions are used. It should be noted that the model results with the vibrational states of $\mathrm{N}_{2}(v)$ and $\mathrm{O}_{2}(v)$ included do not always fit the data. These discrepancies are probably due to the uncertainties in the model inputs, such as a possible inability of the MSIS-86 model to accurately predict the thermospheric response to this storm above Millstone Hill, and uncertainties in EUV fluxes, rate coefficients, and the flow of ionization between the ionosphere and plasmasphere, and possible horizontal divergence of the flux of ionization above the station.

The deviations of $\left[\mathrm{N}_{2}(v)\right]$ from $\left[\mathrm{N}_{2}(v)\right]_{B}$ and $\left[\mathrm{O}_{2}(v)\right]$ from $\left[\mathrm{O}_{2}(v)\right]_{B}$ in the $\mathrm{F}$ region of the ionosphere affect the recombination rate of $\mathrm{O}^{+}\left({ }^{4} \mathrm{~S}\right)$ ions and the heating rate of electrons due to the de-excitation reactions of vibrationally excited molecular nitrogen and oxygen, and the result of these deviations is the difference between solid and dotted lines in Fig. 2. We found that the $\mathrm{N}_{2}(v)$ and $\left[\mathrm{O}_{2}(v)\right]$ Boltzmann distribution assumption leads to the increase of the calculated daytime $\mathrm{NmF} 2$ up to a factor of 1.44 and to the changes in $T_{e m}$ up to $686 \mathrm{~K}$ in comparison with $\mathrm{NmF} 2$ and $T_{e m}$ calculated by using of the non-Boltzmann vibrational distribution of $\mathrm{N}_{2}$ and $\mathrm{O}_{2}$.

Our study shows the Boltzmann vibrational $\mathrm{N}_{2}$ and $\mathrm{O}_{2}$ distribution assumptions give better agreement between measured and modeled $\mathrm{NmF} 2$ and $T_{e m}$ than the non-Boltzmann vibrational distribution of $\mathrm{N}_{2}$ and $\mathrm{O}_{2}$ during 18-21 March. On 22 March only, the non-Boltzmann vibrational distribution model results agree better with the observations in comparison to the results from the model with the Boltzmann vibrational distribution of $\mathrm{N}_{2}$ and $\mathrm{O}_{2}$. The Boltzmann and nonBoltzmann vibrational $\mathrm{N}_{2}$ and $\mathrm{O}_{2}$ distribution assumptions produce a comparable degree of agreement between modeled and measured electron density and temperature on 16 and 23 March.

The results of calculating $\left[\mathrm{N}_{2}(v)\right] /\left[\mathrm{N}_{2}(v)\right]_{B}$, $\left[\mathrm{O}_{2}(v)\right] /\left[\mathrm{O}_{2}(v)\right]_{B}, T_{v i b}, T_{v}$, and $T_{n}$ at $\mathrm{hmF} 2$ are presented in Fig. 3. The present study suggests that the deviations of $\left[\mathrm{N}_{2}(v)\right]$ and $\left[\mathrm{O}_{2}(v)\right]$ from the Boltzmann distributions of Eqs. (5) and (6) are not significant at vibrational levels $v<3 \quad\left(\left[\mathrm{~N}_{2}(1)\right] /\left[\mathrm{N}_{2}(1)\right]_{B}=0.72-1.07, \quad\left[\mathrm{O}_{2}(1)\right] /\right.$ $\left[\mathrm{O}_{2}(1)\right]_{B}=0.99-1.16, \quad\left[\mathrm{~N}_{2}(2)\right] /\left[\mathrm{N}_{2}(2)\right]_{B}=0.88-1.46$, $\left.\left[\mathrm{O}_{2}(2)\right] /\left[\mathrm{O}_{2}(2)\right]_{B}=0.88-1.05\right)$. The calculated distributions of $\mathrm{N}_{2}(v)$ and $\mathrm{O}_{2}(v)$ are highly non-Boltzmann at vibrational levels $v>2\left(\left[\mathrm{~N}_{2}(3)\right] /\left[\mathrm{N}_{2}(3)\right]_{B}=0.97-7.8\right.$, $\left[\mathrm{N}_{2}(4)\right] /\left[\mathrm{N}_{2}(4)\right]_{B}=0.9-49.0,\left[\mathrm{~N}_{2}(5)\right] /\left[\mathrm{N}_{2}(5)\right]_{B}=1.4-790$, $\left[\mathrm{O}_{2}(3)\right] /\left[\mathrm{O}_{2}(3)\right]_{B}=0.59-1.00, \quad\left[\mathrm{O}_{2}(4)\right] /\left[\mathrm{O}_{2}(4)\right]_{B}=$ $\left.0.37-0.98,\left[\mathrm{O}_{2}(5)\right] /\left[\mathrm{O}_{2}(5)\right]_{B}=0.23-0.99\right)$. From the diurnal variations of the calculated vibrational and neutral temperatures shown in Fig. 3 it follows that $T_{v i b}<T_{n}$ and $T_{v}<T_{n}$ are realized in the atmosphere for the nighttime periods where the production frequencies of $\mathrm{O}_{2}(v)$ and $\mathrm{N}_{2}(v)$ are low. This means that for these periods the populations of $\mathrm{O}_{2}(v)$ or $\mathrm{N}_{2}(v)$ are less than the populations for a Boltzmann distribution with temperature $T_{n}$. During daytime $T_{v i b}$ and $T_{v}$ are larger than $T_{n}$ due to the enhanced thermal excitation of $\mathrm{O}_{2}$ and $\mathrm{N}_{2}$ as a result of high thermal electron temperatures at F2-region altitudes. We found that $-50 \mathrm{~K} \leq T_{v i b}-$ $T_{n} \leq 358 \mathrm{~K}$ and $-99 \mathrm{~K} \leq T_{v}-T_{n} \leq 840 \mathrm{~K}$. The value of the vibrational temperature was not more than $1784 \mathrm{~K}$ for $\mathrm{O}_{2}$ and $2334 \mathrm{~K}$ for $\mathrm{N}_{2}$. The calculations also showed that the $\mathrm{O}_{2}$ and $\mathrm{N}_{2}$ vibrational temperatures during the quiet periods are smaller then during the magnetic storm periods.

The excitation of $\mathrm{N}_{2}$ and $\mathrm{O}_{2}$ by thermal electrons provides the main contribution to the values of $\mathrm{O}_{2}(v)$ and $\mathrm{N}_{2}(v)$ vibrational excitations if the electron temperature is higher than about $1600-1800 \mathrm{~K}$ at F-region altitudes (Pavlov, 1988, 1997, 1998b; Pavlov and Namgaladze, 1988; Pavlov and Buonsanto, 1997). The values of $T_{v i b}-T_{n}$ and $T_{v}-T_{n}$ increase with increasing the thermal electron production frequencies, $\mathrm{W}\left(\mathrm{O}_{2}\right)$ and $\mathrm{W}\left(\mathrm{N}_{2}\right)$, of the $\mathrm{O}_{2}$ and $\mathrm{N}_{2}$ vibrational quanta, correspondingly. Pavlov (1998a) found that the value of $\mathrm{W}\left(\mathrm{N}_{2}\right)$ increases with increasing $T_{e}$ in the temperature range 300-6000 K, and due to this dependence, the value of $T_{v}$ increases with increasing $T_{e}$. The value of $\mathrm{W}\left(\mathrm{O}_{2}\right)$ also increases with the increase of $T_{e}$ (Pavlov, 1998c). However, unlike the dependence of $\mathrm{W}\left(\mathrm{N}_{2}\right)$ on $T_{e}$, this increase of $\mathrm{W}\left(\mathrm{O}_{2}\right)$ is small in the electron temperature range $2000-4000 \mathrm{~K}$. As a result, $\mathrm{W}\left(\mathrm{O}_{2}\right) \approx$ const. $N_{e}$, and this leads to $T_{v}>T_{v i b}$.

Schmeltekopf et al. (1968) measured $K\left(T_{v}\right)$ over the vibrational temperature range $300-6000 \mathrm{~K}$, and found the $K_{v} / K_{0}$ ratios from the measured $K\left(T_{v}\right)$ only for $T_{n}=T_{i}=300 \mathrm{~K}$. The dependence of these rate coefficients on the neutral and ion temperatures was found for the first time by Hierl et al. (1997). The measurements of Hierl et al. (1997) have reduced the uncertaintes in the temperature-dependent reaction rates for $\mathrm{O}^{+}\left({ }^{4} \mathrm{~S}\right)+$ $\mathrm{N}_{2}(v>0)$ and $\mathrm{O}^{+}\left({ }^{4} \mathrm{~S}\right)+\mathrm{O}_{2}(v>0)$. Therefore, an accurate estimate of the role of $\mathrm{N}_{2}(v>0)$ and $\mathrm{O}_{2}(v>0)$ in the ionosphere can be made by comparing ionospheric model calculations with and without these species included.

Figure 4 shows the comparison between the measured (crosses) and calculated (lines) NmF2 (bottom panel), hmF2 (middle panel), and the electron temperature at the F2 peak altitude (top panel) above Millstone Hill for the magnetically quiet and disturbed period 1623 March, 1990. Solid lines show the results obtained from the IZMIRAN model with effects of $\mathrm{N}_{2}(v>0)$ and $\mathrm{O}_{2}(v>0)$ on the $\mathrm{O}^{+}\left({ }^{4} \mathrm{~S}\right)$ loss rate (see Eq. 3) using the Boltzmann populations of the first five vibrational levels of $\mathrm{N}_{2}(v)$ and $\mathrm{O}_{2}(v)$. Dotted lines represent the IZMIRAN model results when $\mathrm{N}_{2}(v>0)$ and $\mathrm{O}_{2}(v>0)$ are not included in the calculations of $L$. Dashed lines give the IZMIRAN model results when $\mathrm{O}_{2}(v>0)$ is included and $\mathrm{N}_{2}(v>0)$ is not included in calculations of $L$. Solid and dotted lines show the results obtained from the IZMIRAN model when the calculated Boltzmann populations of $\mathrm{N}_{2}(v)$ and $\mathrm{O}_{2}(v)$ are used in the heating rate of electrons due to the de-excitation reactions of $\mathrm{N}_{2}(v)$ and $\mathrm{O}_{2}(v)$.

As Fig. 4 shows, there is a large increase in the modeled NmF2 without the vibrational excited nitrogen and oxygen. Both the daytime and nighttime densities are not reproduced by the model without $\mathrm{N}_{2}(v>0)$ and 


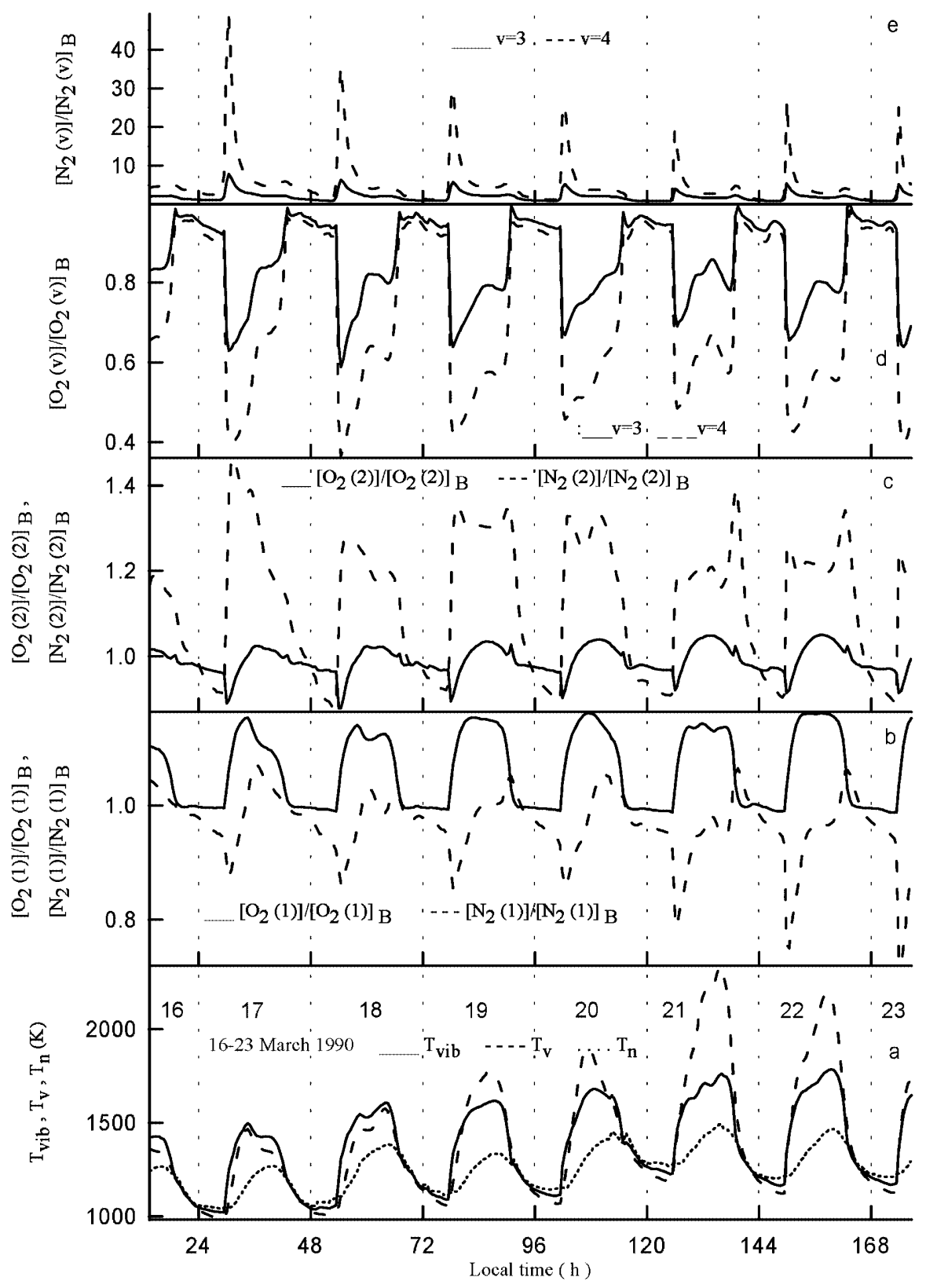

Fig. 3a-e. The time variations of the vibrational temperatures of $\left[\mathrm{N}_{2}\right]$ and $\left[\mathrm{O}_{2}\right]$, $\mathbf{a}$ and the neutral temperature, $\mathbf{b}-\mathbf{e}$ and populations of the first five vibrational levels of $\mathrm{N}_{2}(v=1,2,3$, and 4) and $\mathrm{O}_{2}(v=1,2,3$, and 4) in comparison with the Boltzmann populations of Eqs. (5) and (6) during the 16-23 March, 1990, period at the F2 peak altitude. The solid lines show the modeled $T_{v i b},\left[\mathrm{O}_{2}(1)\right] /\left[\mathrm{O}_{2}(1)\right]_{B},\left[\mathrm{O}_{2}(2)\right] /$ $\left[\mathrm{O}_{2}(2)\right]_{B},\left[\mathrm{O}_{2}(3)\right] /\left[\mathrm{O}_{2}(3)\right]_{B}$, and $\left[\mathrm{N}_{2}(3)\right] /$ $\left[\mathrm{N}_{2}(3)\right]_{B}$ The dashed lines show the modeled $T_{v},\left[\mathrm{~N}_{2}(1)\right] /\left[\mathrm{N}_{2}(1)\right]_{B},\left[\mathrm{~N}_{2}(2)\right] /\left[\mathrm{N}_{2}(2)\right]_{B}$, $\left[\mathrm{N}_{2}(4)\right] /\left[\mathrm{N}_{2}(4)\right]_{B}$, and $\left[\mathrm{O}_{2}(4)\right] /\left[\mathrm{O}_{2}(4)\right]_{B}$. The dotted line shows the modeled $T_{n}$. The local time start is 13:00
$\mathrm{O}_{2}(v>0)$ in the loss rate of $\mathrm{O}^{+}\left({ }^{4} \mathrm{~S}\right)$ ions, and inclusion of vibrationally excited $\mathrm{N}_{2}$ and $\mathrm{O}_{2}$ in $L$ brings the model and data into better agreement. The comparison of solid and dashed lines in Fig. 4 shows that the increase in the $\mathrm{O}^{+}+\mathrm{N}_{2}$ rate factor due to the vibrational excited nitrogen leads to the decrease of the calculated daytime $\mathrm{NmF} 2$ up to a factor of 1.8. The comparison between dotted and dashed lines shows that the increase in the $\mathrm{O}^{+}+\mathrm{O}_{2}$ loss rate due to vibrationally excited $\mathrm{O}_{2}$ produces factors of 1.7 reductions in the daytime peak density. The resulting effect of $\mathrm{N}_{2}(v>0)$ and $\mathrm{O}_{2}(v>0)$ included in $L$ on the $\mathrm{NmF} 2$ is the decrease of the calculated daytime NmF2 up to a factor of 2.8 for Boltzmann populations of $\mathrm{N}_{2}(v)$ and $\mathrm{O}_{2}(v)$, and up to a factor of 3.5 for non-Boltzmann populations of $\mathrm{N}_{2}(v)$ and $\mathrm{O}_{2}(v)$. The effects of vibrationally excited $\mathrm{O}_{2}$ and $\mathrm{N}_{2}$ on $N_{e}$ are most pronounced during daytime.
The IZMIRAN model used was updated many times in comparison with the IZMIRAN model used by Pavlov and Buonsanto (1997). As a result, the discrepancies between the modeled and measured ionospheric parameters are less than those found by Pavlov and Buonsanto (1997).

Richards et al. (1994) compared observed values of $\mathrm{NmF} 2, \mathrm{hmF} 2$, and $T_{e}$ at Millstone Hill with FLIP model results for the March 1990 storm. The FLIP model without $\mathrm{N}_{2}(v)$ gives better agreement between the measured and modeled NmF2 on March 18-20 but worse agreement on March 21-23 than FLIP with $\mathrm{N}_{2}(v)$ included. Although the FLIP and IZMIRAN models are similar in most respects, there are several differences between them (Pavlov et al., 1999). We believe that the differences between the FLIP model used by Richards et al. (1994) and the IZMIRAN model in calculations of 


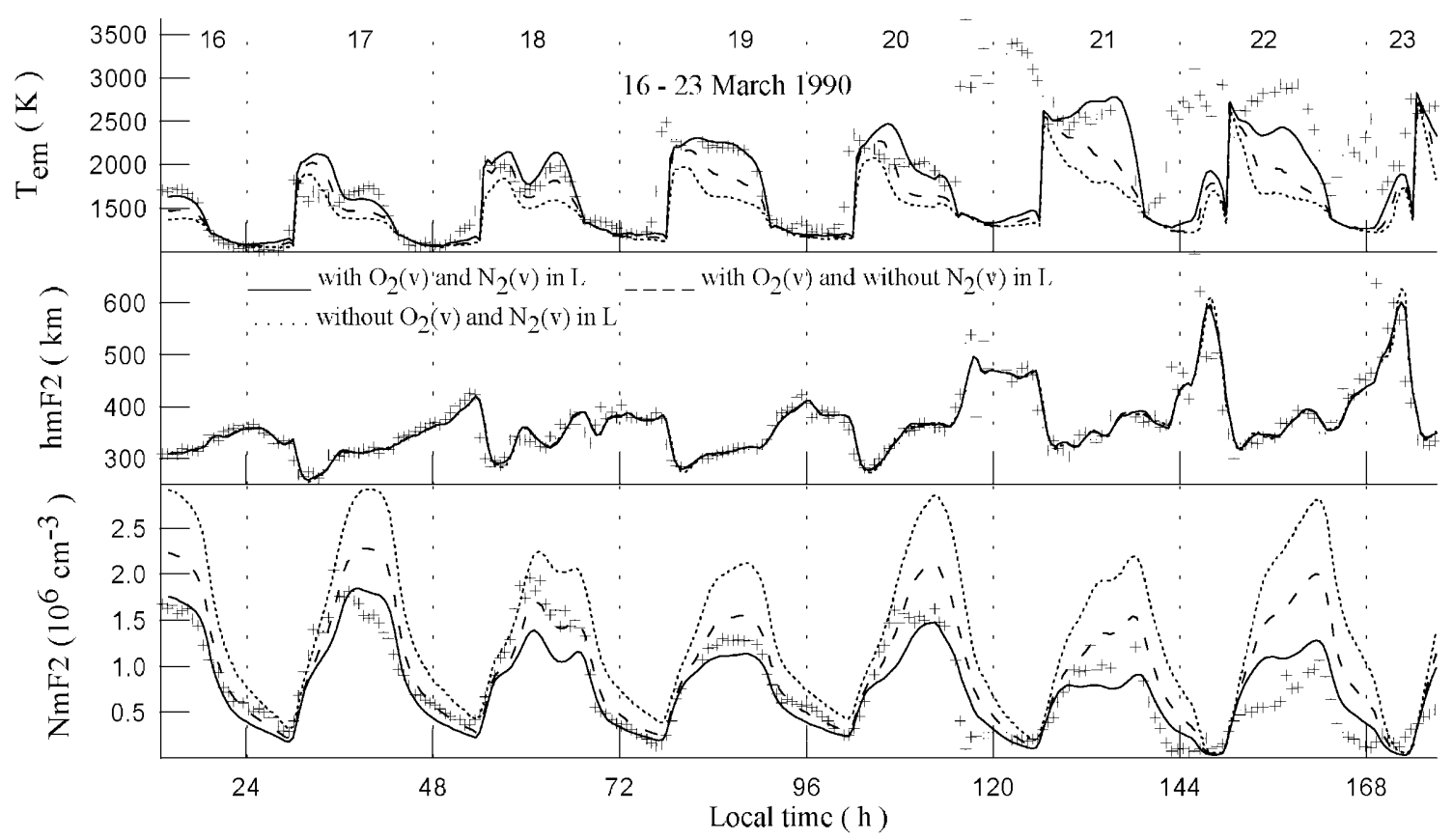

Fig. 4. Observed (crosses) and calculated (lines) NmF2 (bottom panel), hmF2 (middle panel), and the electron temperature, $T_{e m}$, at the F2 peak altitude (top panel) above Millstone Hill for the magnetically quiet and disturbed period 16-23 March, 1990. Solid lines show the modeled results obtained with effects of $\mathrm{N}_{2}(v>0)$ and $\mathrm{O}_{2}(v>0)$ on the $\mathrm{O}^{+}\left({ }^{4} \mathrm{~S}\right)$ loss rate, $L$, (see Eq. 3) using the Boltzmann populations of the first five vibrational levels of $\mathrm{N}_{2}(v)$ and $\mathrm{O}_{2}(v)$.

the loss rate of $\mathrm{O}^{+}\left({ }^{4} \mathrm{~S}\right)$ ions, cooling rate of thermal electrons, and the model of solar flux (see also Pavlov and Buonsanto, 1997) determine the differences between the IZMIRAN and FLIP model results for the March 1990 magnetic storm.

\subsection{Electron temperature}

The top panel of Fig. 4 shows the diurnal variations of the measured and modeled electron and ion temperatures at the F2-peak altitude. As can be seen, the effects of adding $\mathrm{N}_{2}(v)$ and $\mathrm{O}_{2}(v)$ on $T_{e}$ are largest during the day, with increases in $T_{e}$ accompanying the decreases in $\mathrm{NmF} 2$. We found that the resulting effect of $\mathrm{N}_{2}(v>0)$ and $\mathrm{O}_{2}(v>0)$ included in $L$ on the electron temperature at the F2 peak altitude is the decrease of the calculated daytime electron temperature up to about $1040 \mathrm{~K}$ for Boltzmann populations of $\mathrm{N}_{2}(v)$ and $\mathrm{O}_{2}(v)$ and up to about $1410 \mathrm{~K}$ for non-Boltzmann populations of $\mathrm{N}_{2}(v)$ and $\mathrm{O}_{2}(v)$. The effects of vibrationally excited $\mathrm{O}_{2}$ and $\mathrm{N}_{2}$ on $T_{e}$ are most pronounced during daytime.

It should be noted that the modeled electron temperature is very sensitive to the electron density, and, as a result, there is a large decrease in the modeled electron temperatures without the vibrational excited nitrogen and oxygen in the model (see upper panel of Fig. 4). Including of vibrationally excited $\mathrm{N}_{2}$ and $\mathrm{O}_{2}$ in the loss rate of $\mathrm{O}^{+}\left({ }^{4} \mathrm{~S}\right)$ ions which brings the measured and modeled electron densities into better agreements
Dotted lines represent the IZMIRAN model results when $\mathrm{N}_{2}(v>0)$ and $\mathrm{O}_{2}(v>0)$ were not included in the calculations of $L$. Dashed lines give the IZMIRAN model results without effects of $\mathrm{N}_{2}(v>0)$ on $L$ when $\mathrm{O}_{2}(v>0)$ was included in the calculations of $L$. The value of $\mathrm{hmF} 2$ from the IZMIRAN model is a fit to data using the modified method of Richards (1991) described by Pavlov and Buonsanto (1997) (see Sect. 2). The local time start is 13:00

tends to give close agreement between measured and modeled electron temperatures.

The relative magnitudes of the cooling rates are of particular interest for understanding the main processes that determine the electron temperature. We found that the energy exchange between electrons and ions, and the electron cooling rates by vibrational excitation of $\mathrm{N}_{2}$ and $\mathrm{O}_{2}$ are the dominant cooling channels above $180 \mathrm{~km}$ during daytime. We found that the contribution of the cooling of electrons by low-lying electronic excitation of $\mathrm{O}_{2}\left(a^{1} \Delta_{g}\right)$ and $\mathrm{O}_{2}\left(b^{1} \Sigma_{g}^{+}\right)$, by excitation of $\mathrm{O}$ to the ${ }^{1} \mathrm{D}$ state, and by rotational excitation of $\mathrm{O}_{2}$ can be neglected above $160 \mathrm{~km}$ altitude as they are not more than $1 \%$ of the total cooling rate during the quiet and geomagnetic storm period 16-23 March, 1990. The atomic oxygen fine structure cooling rate of thermal electrons is not the dominant electron cooling process in agreement with the conclusions of Pavlov and Berrington (1999).

During the period 16-23 March the agreement between the measured and modeled electron temperatures is good except for the nighttime periods 20-23 March when high electron temperatures were observed at F2 peak altitudes. A detailed statistical study of the nighttime electron temperature enhancements over Millstone Hill has been published by Garner et al. (1994), who found that the anomalous nighttime temperature events are observed over less than a third of the time studied in the fall and spring months. There is a close relationship between electron temperature and electron 
density at night. However, Fig. 4 shows that even when the IZMIRAN model accurately reproduces the electron density, it does not always reproduce the observed electron temperature.

The IZMIRAN model solves the Boltzmann equation for photoelectron flux along a centered - dipole magnetic field line to calculate the heating rate of the electron gas by photoelectrons using the numerical method of Krinberg and Tachilin (1984). The energy lost by photoelectrons in heating the plasma in the plasmasphere is calculated using the analytical equation for the plasmaspheric transparency, $\mathrm{P}(\mathrm{E})$, (Krinberg and Matafonov, 1978; Krinberg and Tachilin, 1984) that determines the probability of the magnetically trapped photoelectrons with an energy, $E$, of entering the magnetically conjugated ionosphere. The transparency depends mainly on a single parameter proportional to the Coulomb cross section and the total content of electrons in the plasmasphere magnetic flux tube (the transparency approaches unity as photoelectrons pass through the plasmasphere without significant absorption, and $P(E)=0$ if photoelectrons are absorbed by the plasmasphere).

The disagreement between the measured and modeled electron temperature could be due to uncertainties of the IZMIRAN model in the amount of the energy deposited in the plasmasphere by ionospheric photoelectrons. However, changing the value of $P(E)$ we have found that the heating provided by trapped photoelectrons cannot account for the observed nighttime high electron temperatures at F2 peak altitudes during the 20-23 March period.

The possible additional sources of the electron gas heating in the plasmasphere, such as wave-particle interactions, which can cause increased photoelectron scattering, and Coulomb collisions between ring current ions and plasmaspheric electrons and ions could be the most plausible mechanisms to explain the observed electron temperature enhancements. The heating could also be caused by heated flux tubes drifting past Millstone Hill due to plasma convection. To model this transfer of plasma, caused by some plasmaspheric electric field (usually of magnetospheric origin), consideration of the perpendicular (with respect to the magnetic field) divergence contribution in the ion equations of continuity arising from perpendicular plasma gradients is needed, and a model of this electric field is required or must be created. The IZMIRAN model cannot take into account the drift of flux tubes because it is a one dimensional model. This is the reason of possible errors of the model.

As a result, following Pavlov (1996, 1997) and Richards and Khazanov (1997), we use a fitting approach. We assume that an additional heating rate, $q$, should be added to the normal photoelectron heating in the electron energy equation in the plasmasphere region above $5000 \mathrm{~km}$ along the magnetic field line to explain these anomalous electron temperature enhancements. We do not know the real time dependence of additional heating, and we can only evaluate the value of $q$ from the comparison of the modeled and measured electron temperatures. We found that good agreement between the measured and modeled nighttime electron temperatures is obtained if $q=0.9 \mathrm{eV} \mathrm{cm}^{-3} \mathrm{~s}^{-1}$ from 20:54 UT on 20 March to 8:54 UT on 21 March, $q=0.5 \mathrm{eV} \mathrm{cm}^{-3} \mathrm{~s}^{-1}$ from 23:54 UT on 21 March to 09:54 UT on $22 \mathrm{March}$, and $q=0.7 \mathrm{eV} \mathrm{cm}^{-1} \mathrm{~s}^{-1}$ from 24:54 UT on 22 March to 03:54 UT on 23 March. The model electron heating due to photoelectrons is less than this required additional heating above $5000 \mathrm{~km}$ during the time periods with the additional heating in the model. The values of $q$ used by the IZMIRAN model between $5000 \mathrm{~km}$ and $12077 \mathrm{~km}$ are less than the values of an equatorial high-altitude heat source found by Balan et al. (1996) in this altitude range.

\section{Conclusions}

The model results were compared to the Millstone Hill incoherent-scatter radar measurements of electron density and temperature for the geomagnetically quiet and disturbed period on 16-23 March, 1990. The model used is an enhanced and updated version of the IZMIRAN model we have steadily developed over the years. The updated model uses the revised electron cooling rates by vibrational and rotational excitation of $\mathrm{O}_{2}$ and $\mathrm{N}_{2}$, and by electron impact excitation of fine structure levels of atomic oxygen given by Pavlov (1998a, c) and Pavlov and Berrington (1999) in calculations of the electron temperature, and the updated elastic and inelastic cross sections of the neutral components of the atmosphere to solve the Boltzmann equation for photoelectron fluxes.

The deviations from the Boltzmann distribution for the first five vibrational levels of $\mathrm{N}_{2}$ and $\mathrm{O}_{2}$ were calculated. The present study suggests that the deviations from the Boltzmann distribution are not significant at the first and second vibrational levels of $\mathrm{N}_{2}$ and $\mathrm{O}_{2}$, and the calculated distributions of $\mathrm{N}_{2}(v)$ and $\mathrm{O}_{2}(v)$ are highly non-Boltzmann at vibrational levels $v>2$. The calculations also showed that the $\mathrm{O}_{2}$ and $\mathrm{N}_{2}$ vibrational temperatures during the quiet periods are less then during the magnetic storm periods. During daytime the high vibrational temperatures stem from the enhanced thermal excitation of $\mathrm{O}_{2}$ and $\mathrm{N}_{2}$ as a result of high thermal electron temperatures at $\mathrm{F} 2$-region altitudes.

We found that the $\mathrm{N}_{2}(v)$ and $\mathrm{O}_{2}(v)$ Boltzmann distribution assumption leads to the increase of the calculated daytime $\mathrm{NmF} 2$ up to a factor of 1.44 and to the changes in $T_{e m}$ up to $686 \mathrm{~K}$ in comparison with $\mathrm{NmF} 2$ and $T_{e m}$ calculated by using of the non-Boltzmann vibrational distribution of $\mathrm{N}_{2}$. Our study shows that the Boltzmann vibrational $\mathrm{N}_{2}(v)$ and $\mathrm{O}_{2}(v)$ distribution assumption gives better agreement between measured and modeled NmF2 and $T_{e m}$ than the nonBoltzmann vibrational distribution of $\mathrm{N}_{2}(v)$ and $\mathrm{O}_{2}(v)$ during 18-21 March. On 22 March only, the $\mathrm{N}_{2}(v)$ and $\mathrm{O}_{2}(v)$ non-Boltzmann vibrational distribution model results agree better with the observations in comparison to the results from the IZMIRAN model with the $\mathrm{N}_{2}(v)$ and $\mathrm{O}_{2}(v)$ Boltzmann vibrational distribution. The 
Boltzmann and non-Boltzmann vibrational $\mathrm{N}_{2}$ and $\mathrm{O}_{2}$ distribution assumptions produce a comparable degree of agreement between modeled and measured electron density and temperature on 16 and 23 March.

The resulting effect of $\mathrm{N}_{2}(v>0)$ and $\mathrm{O}_{2}(v>0)$ included in $L$ on the $\mathrm{NmF} 2$ is the decrease of the calculated daytime $\mathrm{NmF} 2$ up to a factor of 2.8 for Boltzmann populations of $\mathrm{N}_{2}(v)$ and $\mathrm{O}_{2}(v)$ and up to a factor of 3.5 for non-Boltzmann populations of $\mathrm{N}_{2}(v)$ and $\mathrm{O}_{2}(v)$. The modeled electron temperature is very sensitive to the electron density, and this decrease in electron density results in the increase of the calculated daytime electron temperature up to about 1040-1410 K at the F2 peak altitude. Both the daytime and nighttime densities are not reproduced by the model without $\mathrm{N}_{2}(v>0)$ and $\mathrm{O}_{2}(v>0)$, and inclusion of vibrationally excited $\mathrm{N}_{2}$ and $\mathrm{O}_{2}$ brings the model and data into better agreement. The effects of vibrationally excited $\mathrm{O}_{2}$ and $\mathrm{N}_{2}$ on the electron density and temperature are most pronounced during daytime.

We have examined the thermal electron energy budget in the mid-latitude ionosphere at solar maximum in March 1990 and evaluated the value of the additional heating rate that should be added to the normal photoelectron heating in the electron energy equation in the plasmasphere region above $5000 \mathrm{~km}$ along the magnetic field line to explain the anomalous electron temperature enhancements during the nighttime periods 20-23 March, 1990. This additional heat source of electrons in the plasmasphere might arise from waveparticle interactions and Coulomb collisions between ring current ions and plasmaspheric electrons and ions. The heating could also be caused by heated flux tubes drifting past Millstone Hill.

Acknowledgements. This work was carried out while A.V. Pavlov was visiting ISAS (Japan). He acknowledges the warm hospitality of ISAS. The authors are grateful for the help of the late M.J. Buonsanto (he passed away suddenly on 20 October, 1999, of a heart attack) and wish to thank J.C. Foster, and other personnel at Millstone Hill Observatory of the Massachusetts Institute of Technology for providing CEDAR Database data. We would like to thank anonymous referees for critical reading of the manuscript as reviewers and for helpful comments.

Topical Editor M. Lester thanks E.J. Bucsela and M. Codrescu for their help in evaluating this paper.

\section{References}

Albritton, D. L., I. Dotan, W. Lindinger, M. McFarland, J. Tellinghuisen, and F. C. Fehsenfeld, Effects of ion speed distributions in flow-drift tube studies on ion-neutral reactions, J. Chem. Phys., 66, 410-421, 1977.

Balan, N., K.-I. Oyama, G. J. Bailey, and T. Abe, Plasmaspheric electron temperature profiles and the effects of photoelectron trapping and an equatorial high-altitude heat source, J. Geophys. Res., 101, 21 689-21 696, 1996.

Buonsanto, M. J., J. C. Foster, and D. P. Sipler, Observations from Millstone Hill during the geomagnetic disturbances of March and April 1990, J. Geophys. Res., 97, 1225 -1243, 1992.

Ferguson, E. E., N. G. Adams, D. Smith, and E. Alge, Rate coefficients at $300 \mathrm{~K}$ for the vibrational energy transfer reactions from $\mathrm{N}_{2}(v=1)$ to $\mathrm{O}_{2}^{+}(v=0)$ and $\mathrm{NO}^{+}(v=0)$, J. Chem. Phys., 80, 6095-6098, 1984.
Garner, T. W., P. G. Richards, and R. H. Comfort, Anomalous nightime electron temperature events over Millstone Hill, J. Geophys. Res., 99, 11 411-11 416, 1994.

Hedin, A. E., MSIS-86 thermospheric model, J. Geophys. Res., 92, 4649-4662, 1987.

Hierl, M. P., I. Dotan, J. V. Seeley, J. M. Van Doren, R. A. Morris, and A. A. Viggiano, Rate constants for the reactions of $\mathrm{O}^{+}$with $\mathrm{N}_{2}$ and $\mathrm{O}_{2}$ as a function of temperature (300-1800 K), J. Chem. Phys., 106, 3540-3544, 1997.

Itikawa, Y., Electron collisions with $\mathrm{N}_{2}, \mathrm{O}_{2}$, and $\mathrm{O}$ : what we do and do not know, Advances in Atomic, Molecular and Optical Physics, 33, 253-273, 1994, Academic Press, New York.

Joshipura, K. N., and P. M. Patel, Cross sections of $\mathrm{e}^{-}-\mathrm{O}$ scattering at intermediate and high energies $\left(E_{i}=8.7-\right.$ 1000 eV), Phys. Rev., 48, 2464-2467, 1993.

Kanic, I., S. Trajmar, and J. C. Nickel, Total electron scattering and electronic state excitations cross sections for $\mathrm{O}_{2}, \mathrm{CO}_{2}$, and $\mathrm{CH}_{4}$, J. Geophys. Res., 98E, 7447-7460, 1992.

Krinberg, I. A., and G. K. Matafonov, Coulomb collision-induced photoelectron trapping by the geomagnetic field and electron gason the heating in the plasmasphere, Anal. Geophys., 34, 89-96, 1978.

Krinberg, I. A., and A. V. Tachilin, Ionosphere and plasmasphere (in Russian), Nauka, Moscow, 1984.

Majeed, T., and D. J. Strickland, New survey of electron impact cross sections for photoelectron and auroral electron energy loss calculations, J. Phys. Chem. Ref. Data, 26, 335-349, 1997.

McFarland, M., D. L. Albritton, F. C. Fehsenfeld, E. E. Ferguson, and A. L. Schmeltekopf, Flow-drift technique for ion mobility and ion-molecule reaction rate constant measurements, II. Positive ion reaction of $\mathrm{N}^{+}, \mathrm{O}^{+}$, and $\mathrm{N}_{2}^{+}$with $\mathrm{O}_{2}$ and $\mathrm{O}^{+}$with $\mathrm{N}_{2}$ from thermal to $2 \mathrm{eV}$, J. Chem. Phys., 59, 6620-6628, 1973.

Pavlov, A. V., The role of vibrationally excited nitrogen in the ionosphere, Pure Appl. Geophys., 127, 529-544, 1988.

Pavlov, A. V., Mechanisms of the electron density depletion in the SAR arc region, Ann. Geophysicae, 14, 211-221, 1996.

Pavlov, A. V., Subauroral red arcs as a conjugate phenomenon: comparison of OV1-10 satellite data with numerical calculations, Ann. Geophysicae., 15, 984-998, 1997.

Pavlov, A. V., New electron energy transfer rates for vibrational excitation of $\mathrm{N}_{2}$, Ann. Geophysicae, 16, 176-182, 1998a.

Pavlov, A. V., The role of vibrationally excited oxygen and nitrogen in the ionosphere during the undisturbed and geomagnetic storm period of 6-12 April 1990, Ann. Geophysicae, 16, 589-601, 1998b.

Pavlov, A. V., New electron energy transfer and cooling rates by excitation of $\mathrm{O}_{2}$, Ann. Geophysicae, 16, 1007-1013, 1998c.

Pavlov, A. V., and A. A. Namgaladze, Vibrationally excited nitrogen in the upper atmosphere. Review paper, Geomagn. Aeron., 28, 607-620, 1988.

Pavlov, A. V., and M. J. Buonsanto, Comparison of model electron densities and temperatures with Millstone Hill observations during undisturbed periods and the geomagnetic storms of March 16-23 and April 6-12, 1990, Ann. Geophysicae, 15, 327344, 1997.

Pavlov, A. V., and K. A. Berrington, Cooling rate of thermal electrons by electron impact excitation of fine structure levels of atomic oxygen, Ann. Geophysicae, 17, 919-924, 1999.

Pavlov, A. V., M. J. Buonsanto, A. C. Schlesier, and P. G. Richards, Comparison of models and data at Millstone Hill during the June 5-11, 1991 storm, J. Atmos. Solar-Terrestrial Phys, 61, 263-279, 1999.

Peterson, J. R., A. Le Padellec, H. Danared, G. H. Dunn, M. Larsson, A. Larson, R. Peverall, C. Stromholm, S. Rosen, M. Ugglas, and W. J. Van der Zande, Dissociative recombination end excitation of $\mathrm{N}_{2}^{+}$: cross sections and product branching ratios, J. Chem. Phys., 108, 1978-1988, 1998.

Radzig, A. A., and B. V. Smirnov, The reference book in atomic and molecular physics (in Russian), Atomizdat, Moscow, 1980.

Richards, P. G., An improved algorithm for determining neutral winds from the height of the F2 peak electron density, J. Geophys. Res., 96, 17 839-17 846, 1991. 
Richards, P. G., and G. W. Khazanov, On the thermal electron energy balance in the ionosphere in January 1993 and June 1990, J. Geophys. Res., 102, 7369-7377, 1997.

Richards, P. G., D. G. Torr, and W. A. Abdou, Effects of vibrational enhancement of $\mathrm{N}_{2}$ on the cooling rate of ionospheric thermal electrons, J. Geophys. Res., 91, 304-310, 1986.

Richards, P. G., D. G.Torr, M. J. Buonsanto, and D. P. Sipler, Ionospheric effects of the March 1990 magnetic storm: comparison of theory and measurements, J. Geophys. Res., 99, 23 359-23 365, 1994.

Robertson, A. G., M. T. Elford, R. W. Crompton, M. A. Morrison, W. Sun, and W. K. Trail, Rotational and vibrational excitation of nitrogen by electron impact, Aust. J. Phys., 50, 441-472, 1997.

Schmeltekopf, A. L., E. E. Ferguson, and F. C. Fehsenfeld, Afterglow studies of the reactions $\mathrm{He}^{+}, \mathrm{He}\left(2^{3} \mathrm{~S}\right)$, and $\mathrm{O}^{+}$with vibrationally excited $\mathrm{N}_{2}$, J. Chem. Phys., 48, 2966-2973, 1968.
Schulz, G. J., A review of vibrational excitation of molecules by electron impact at low energies, in Principles of laser plasmas, Ed. G. Berkefi, Interscience, New York, 1976, pp 33-76.

St.-Maurice, J.-P., and D. G. Torr, Nonthermal rate coefficients in the ionosphere: The reactions of $\mathrm{O}^{+}$with $\mathrm{N}_{2}, \mathrm{O}_{2}$ and $\mathrm{NO}$, J. Geophys. Res., 83, 969-977, 1978.

Tobiska, W. K., and F. G. Eparvier, EUV97: Improvements to EUV irradiance modeling in the soft X-rays and FUV, Solar Phys., 177, 147-159, 1998.

Titheridge, J. E., Model results for the ionospheric E region: solar and seasonal changes, Ann. Geophysicae, 15, 63-78, 1997.

Van Zandt, T. E., and T. F. O'Malley, Rate coefficient for the reaction of $\mathrm{O}^{+}$with vibrationally excited $\mathrm{N}_{2}, J$. Geophys. Res., 78, 6818-6820, 1973.

Williams, J. F., and L. J. Allen, Low-energy elastic scattering of electrons from atomic oxygen, J. Phys. B: At. Mol. Opt. Phys., 22, 3529-3539, 1989. 